\title{
Variability, Predictability, and Race Factors Affecting Performance in Elite Biathlon
}

\author{
Øyvind Skattebo and Thomas Losnegard
}

\begin{abstract}
Purpose: To investigate variability, predictability, and smallest worthwhile performance enhancement in elite biathlon sprint events. In addition, the effects of race factors on performance were assessed. Methods: Data from 2005 to 2015 including $>10,000$ and $>1000$ observations for each sex for all athletes and annual top-10 athletes, respectively, were included. Generalized linear mixed models were constructed based on total race time, skiing time, shooting time, and proportions of targets hit. Withinathlete race-to-race variability was expressed as coefficient of variation of performance times and standard deviation (SD) in proportion units (\%) of targets hit. The models were adjusted for random and fixed effects of subject identity, season, event identity, and race factors. Results: The within-athlete variability was independent of sex and performance standard of athletes: $2.5-3.2 \%$ for total race time, $1.5-1.8 \%$ for skiing time, and $11-15 \%$ for shooting times. The SD of the proportion of hits was $\sim 10 \%$ in both shootings combined (meaning \pm 1 hit in 10 shots). The predictability in total race time was very high to extremely high for all athletes (ICC .78-.84) but trivial for top-10 athletes (ICC .05). Race times during World Championships and Olympics were $\sim 2-3 \%$ faster than in World Cups. Moreover, race time increased by $\sim 2 \%$ per $1000 \mathrm{~m}$ of altitude, by $\sim 5 \%$ per $1 \%$ of gradient, by $1-2 \%$ per $1 \mathrm{~m} / \mathrm{s}$ of wind speed, and by $\sim 2-4 \%$ on soft vs hard tracks. Conclusions: Researchers and practitioners should focus on strategies that improve biathletes' performance by at least $0.8-0.9 \%$, corresponding to the smallest worthwhile enhancement $(0.3 \times$ within-athlete variability $)$.
\end{abstract}

Keywords: biathletes, intraclass correlation, reliability, skiing, shooting

Biathlon is a complex Winter Olympic sport that combines intensive cross-country skiing with high-precision rifle marksmanship. Depending on the competition format, an event consists of 3 to 5 skiing laps of 2 to $4 \mathrm{~km}$ interspersed by 2 to 4 shootings, each consisting of 5 shots. The combination of high heart rates and fatigue when entering the shooting range, ${ }^{1}$ the time pressure when shooting, and the fact that the athletes receive a penalty loop of $150 \mathrm{~m}$ or 1 minute added to the total time for each target missed make the sport extremely challenging.

Analysis of the smallest worthwhile performance enhancement in elite sport provides useful information for coaches and scientists to evaluate the magnitude and meaningfulness of different types of interventions (training, tapering, ergogenic aids, etc). The smallest worthwhile enhancement is considered to be 0.3 times the standard deviation of an elite athlete's performance (withinathlete race-to-race variability), which represents 1 extra medal per 10 competitions for an elite athlete already winning medals regularly. ${ }^{2}$ Over the last decade, there has been growing interest in determining the variability of performance times in elite sport including rowing $(0.7-1.4 \%),{ }^{3}$ cycling $(0.4-2.4 \%),{ }^{4}$ speed skating

\footnotetext{
(C) 2018 The Authors. Published by Human Kinetics, Inc. This is an Open Access article distributed under the terms of the Creative Commons Attribution License CC BY NC 4.0, which permits unrestricted noncommercial use, distribution, and reproduction in any medium, provided the original work is properly cited, the new use includes a link to the license, and any changes are indicated. See http:// creativecommons.org/licenses/by-nc/4.0. This license does not cover any third-party material which may appear with permission in the article. For commercial use, permission should be requested from Human Kinetics, Inc., through the Copyright Clearance Center (http://www.copyright.com).
}

The authors are with the Dept of Physical Performance, Norwegian School of Sport Sciences, Oslo, Norway. Skattebo (oyvind.skattebo@nih.no) is corresponding author.
$(0.3-1.0 \%),{ }^{5}$ swimming $(0.6-1.0 \%),{ }^{6}$ orienteering $(3.2-7.0 \%),{ }^{7}$ and cross-country skiing $(1.1-1.4 \%){ }^{8}$ However, due to substantial variation between sports $(0.3-7.0 \%)$, sport-specific variability seems crucial to estimate the smallest worthwhile enhancement. Even though the variability in the similar sport of cross-country skiing has been established, the addition of shooting in biathlon could potentially influence the variability, since more variables affect the overall performance.

Moreover, knowledge about the isolated variability of performance variables (ie, shooting time, proportion of targets hit, and skiing time) and how race factors like altitude, snow condition, wind conditions, and course profiles affect performance (and thereby the variability of performance) seems important in optimizing training preparation and competition strategies. Furthermore, winning a gold medal in biathlon requires not only exceptional aerobic power, an efficient technique, and high-precision rifle marksmanship ${ }^{9-11}$ but also the ability to achieve peak performance at the right time. ${ }^{12}$ Therefore, examining performance differences between major international championships (Olympics and World Championships) and World Cup (WC) races could be beneficial for evaluation and optimization of training preparation.

Thus, the aims of the present study were to estimate the variability and predictability in skiing time, shooting time, proportion of targets hit, and overall performance in elite biathlon. In addition, the effects of race factors and competition importance (WC vs World Championship and Olympics) were assessed.

\section{Methods}

\section{Performance Data}

In biathlon, the athletes compete in 4 solo events. These are sprints (38\% of all races the last $10 \mathrm{y}$ ), pursuits (30\%), individuals (13\%), 
and mass starts $(19 \%)$. In the present study the sprint event was analyzed, since it constitutes the largest proportion of the races and uses the interval-start time-trial format. The sprint event consists of 3 laps of $\sim 2.5 / 3.3 \mathrm{~km}$ (women/men) interspersed by 1 prone and 1 standing shooting, with the athletes receiving a $150-\mathrm{m}$ penalty loop for each target missed. Official race times and course information from Olympic, World Championship, and WC events were extracted from the International Biathlon Union's (IBU) website (www.biathlonworld.com) for 2005 to 2015. Data from 109 and 110 races were extracted for men and women, respectively (Tables 1 and 2). As all data existed in the public domain and no athletes were named, no written informed consent was obtained.

\section{Statistical Analysis}

The linear mixed-modeling procedure in the IBM SPSS Statistics package (version 21; IBM, Armonk, NY) was used to analyze total race time, skiing time, and prone and standing shooting times. These performance times were log-transformed before modeling to limit bias arising from nonuniformity of error, and, thereafter, effects and standard deviations (SD) were back-transformed to percentages to yield percentage effects and the coefficient of variation $(\mathrm{CV})$, respectively. ${ }^{13}$

The shooting result was analyzed as the proportion of successful shots at a shooting (n hits out of 5) or combined for both shootings (n hits out of 10) using logistic regression (the Glimmix procedure) in SAS university edition (SAS Studio; SAS Institute

Table 1 Number of Athletes and Races Entered for Each Athlete in World Cup, World Championship, and Olympic Sprint Events from Season 2005 to 2015 for All Athletes and for Annual Top-10 Athletes

\begin{tabular}{llccc}
\hline & & \multicolumn{2}{c}{ No. of races } \\
\cline { 3 - 5 } & & No. of athletes & Mean \pm SD & Max \\
\hline \multirow{2}{*}{ Men } & All athletes & 556 & $20 \pm 23$ & 97 \\
& Top-10 athletes & 46 & $22 \pm 14$ & 58 \\
\multirow{3}{*}{ Women } & All athletes & 474 & $21 \pm 21$ & 104 \\
& Top-10 athletes & 43 & $24 \pm 17$ & 67 \\
\hline
\end{tabular}

Inc, Cary, NC). Briefly, the procedure converts proportions to log of odds before modeling, allowing for values between $-\infty$ and $+\infty$. After modeling, log of odds and odds ratios were converted back to proportions and proportion ratios before interpretation. ${ }^{14}$

Separate analyses were performed for each sex on all athletes and subgroups of the annual top-10 athletes. The annual top-10 athletes were identified from each season's WC sprint scores (www. biathlonresults.com) and pooled.

The fixed effects in the model analyzing the total race time were race length (log-transformed, numeric linear), competition importance ( 2 levels: World Championship or Olympics vs WC), altitude of the stadium (numeric linear), snow conditions (2 levels, hardpacked vs soft conditions, based on the official ratings: soft or wet or powder vs hard or packed or hardpacked or icy), track gradient (numeric linear; the track's accumulated ascents, total meters climbed, divided by race length and given as a percentage), competition season (numeric linear), and the wind speed at the shooting range (numeric linear). The analysis of the skiing time included all the aforementioned fixed effects except wind speed, and the analysis of prone and standing shooting times and proportion of hits included wind speed, season, altitude, and competition importance. The analysis of performance times included the random effects of competition identity (differences between competitions mean times not accounted for by the fixed effects), athlete identity (pure differences between athletes' mean ability), athlete $\times$ season (within-athlete variation between seasons), and the model residual (within-athlete within-season race-to-race variability). However, in addition to random effects of competition identity, athlete identity, and athlete $\times$ season, the logistic-regression model included a multiplicative overdispersion factor instead of the model residual as in the mixed models.

The generalized mixed linear models were run with the default option of allowing estimation of only positive variances for the random effects, and negative variances were therefore set to zero by the modeling procedure. This happened twice for the random effect of athlete identity when analyzing top-10 athletes. Therefore, zeros in Table 3 should be interpreted as representing negligible between-athletes variability.

Plots of residuals versus predicted values from each of the analyses showed no evidence of nonuniformity of error.

Table 2 Characteristics of the Sprint Races Included in the Study Divided into World Cups and Championship Races (Olympics and World Championships), Mean \pm SD

\begin{tabular}{|c|c|c|c|c|}
\hline & \multicolumn{2}{|c|}{ Men $(n=109)$} & \multicolumn{2}{|c|}{ Women $(n=110)$} \\
\hline & World Cup ( $n=98)$ & Championship $(n=11)$ & World Cup $(n=99)$ & Championship $(n=11)$ \\
\hline Total race time (min) & $26.0 \pm 1.6$ & $25.4 \pm 1.3$ & $23.0 \pm 1.7$ & $22.3 \pm 1.2$ \\
\hline Skiing time (min) & $23.6 \pm 1.4$ & $22.9 \pm 1.2$ & $20.3 \pm 1.5$ & $19.5 \pm 0.9$ \\
\hline Prone shooting time (s) & $31.0 \pm 4.5$ & $30.7 \pm 5.1$ & $33.7 \pm 5.9$ & $33.7 \pm 6.0$ \\
\hline Standing shooting time (s) & $28.2 \pm 5.6$ & $28.5 \pm 6.3$ & $32.4 \pm 5.9$ & $33.4 \pm 7.5$ \\
\hline Proportion hit prone $(\%)$ & $88 \pm 16$ & $86 \pm 17$ & $87 \pm 16$ & $87 \pm 18$ \\
\hline Proportion hit standing (\%) & $83 \pm 18$ & $81 \pm 17$ & $81 \pm 19$ & $80 \pm 20$ \\
\hline Altitude (m) & $760 \pm 487$ & $842 \pm 555$ & $749 \pm 489$ & $842 \pm 555$ \\
\hline Total course length (m) & $10,124 \pm 266$ & $10,124 \pm 226$ & $7635 \pm 169$ & $7635 \pm 177$ \\
\hline Total climb (m) & $343 \pm 37$ & $346 \pm 33$ & $256 \pm 34$ & $250 \pm 22$ \\
\hline Gradient $(\%)$ & $3.4 \pm 0.4$ & $3.4 \pm 0.3$ & $3.3 \pm 0.4$ & $3.3 \pm 0.3$ \\
\hline Wind $(\mathrm{m} / \mathrm{s})$ & $1.2 \pm 1.0$ & $1.6 \pm 1.7$ & $1.2 \pm 1.1$ & $1.6 \pm 1.8$ \\
\hline
\end{tabular}

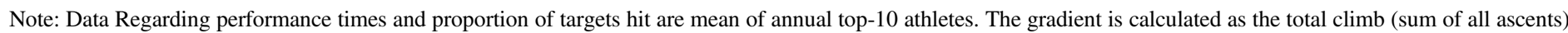
divided by the total race length and given as percentage. 
Table 3 Within- and Between-Athletes Variability in Performance Times Expressed as CV (\%) and the Predictability of Performance Times Expressed as Within- and Between-Seasons ICC for the Total Race Time, Skiing Time, and Prone and Standing Shooting Times for All Athletes and for Annual Top-10 Athletes

\begin{tabular}{|c|c|c|c|c|c|c|c|c|c|c|}
\hline & \multicolumn{5}{|c|}{ All Athletes } & \multicolumn{5}{|c|}{ Top-10 Athletes } \\
\hline & \multicolumn{2}{|c|}{ Within-Athlete CV } & \multirow[b]{2}{*}{$\begin{array}{l}\text { Between- } \\
\text { athletes } \\
\text { CV }\end{array}$} & \multirow[b]{2}{*}{$\begin{array}{l}\text { Within- } \\
\text { season } \\
\text { ICC }\end{array}$} & \multirow[b]{2}{*}{$\begin{array}{l}\text { Between- } \\
\text { seasons } \\
\text { ICC }\end{array}$} & \multicolumn{2}{|c|}{ Within-Athlete CV } & \multirow[b]{2}{*}{$\begin{array}{c}\text { Between- } \\
\text { athletes } \\
\text { CV }\end{array}$} & \multirow[b]{2}{*}{$\begin{array}{c}\text { Within- } \\
\text { season } \\
\text { ICC }\end{array}$} & \multirow[b]{2}{*}{$\begin{array}{c}\text { Between- } \\
\text { seasons } \\
\text { ICC }\end{array}$} \\
\hline & $\begin{array}{l}\text { Within } \\
\text { season }\end{array}$ & $\begin{array}{l}\text { Between } \\
\text { seasons }\end{array}$ & & & & $\begin{array}{l}\text { Within } \\
\text { season }\end{array}$ & $\begin{array}{l}\text { Between } \\
\text { seasons }\end{array}$ & & & \\
\hline \multicolumn{11}{|l|}{ Men } \\
\hline total race time & 2.7 & 3.1 & 6.2 & .84 & .79 & 2.5 & 2.5 & 0.6 & .05 & .05 \\
\hline skiing time & 1.7 & 2.2 & 5.3 & .91 & .85 & 1.5 & 1.6 & 0.8 & .25 & .18 \\
\hline prone shooting time & 11.8 & 12.9 & 14.8 & .63 & .56 & 11.4 & 11.7 & 6.8 & .30 & .26 \\
\hline standing shooting time & 15.0 & 16.1 & 14.7 & .53 & .46 & 14.9 & 15.2 & 8.7 & .28 & .26 \\
\hline \multicolumn{11}{|l|}{ Women } \\
\hline total race time & 3.2 & 3.7 & 5.8 & .78 & .72 & 2.9 & 2.9 & 0.7 & .05 & .05 \\
\hline skiing time & 1.8 & 2.5 & 5.1 & .90 & .80 & 1.5 & 1.6 & 1.3 & .52 & .40 \\
\hline prone shooting time & 11.8 & 13.0 & 12.8 & .58 & .49 & 11.0 & 11.7 & 6.7 & .34 & .26 \\
\hline standing shooting time & 14.9 & 15.9 & 13.5 & .49 & .42 & 13.9 & 14.3 & 8.3 & .30 & .26 \\
\hline
\end{tabular}

Abbreviations: $\mathrm{CV}$, coefficient of variation; ICC, intraclass correlation coefficient

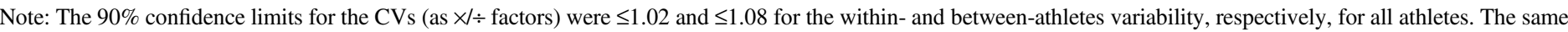

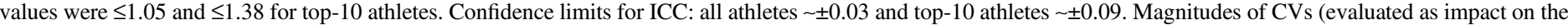

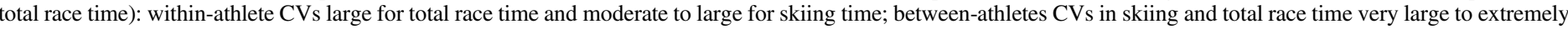
large for all athletes and small for top-10 athletes; CVs regarding shooting times trivial.

Performance times that had standardized residuals $>5.0$ were determined as outliers and removed before reanalyzing. ${ }^{13}$ These values represent performances far worse than normal for a given biathlete (109 total times, skiing times, and shooting times were removed).

CVs of performance times representing within-athlete withinseason race-to-race variability, within-athlete between-seasons race-to-race variability, pure between-athletes variability, and between-events variability were calculated as the square root of the model residual, the square root of the sum of the residual and the athlete identity $\times$ season variances, the square root of the variance represented by athlete identity, and the square root of the variance represented by competition identity, respectively.

For analysis of the proportion of hits, random-effect estimates from the Glimmix procedure gave the variance in log odds ratios. These were subsequently converted to SD as proportion ratios ${ }^{14}$ and used together with the mean proportion of hits to calculate the SD of random effects as proportion units in percentages. The $\mathrm{SD}$ representing within-athlete within-year variability was calculated as the square root of the product of the overdispersion factor $(k)$ and the binomial sampling variance associated with the probability of hits ( $p$; where the mean proportion of targets hit was used as $p$ ) at $\mathrm{n}$ targets (5 or 10 shots) and given as a percentage: $100 \times \sqrt{[(p(1-p) / \mathrm{n}) k]}$.

A spreadsheet was used to interpret and compare effects, ${ }^{15}$ and all magnitude-based inferences were mechanistic. The probabilistic terms to describe beneficial, harmful, or trivial effects were based on the following scale: $<0.5 \%$, most unlikely; $0.5 \%$ to $5 \%$, very unlikely; $5 \%$ to $25 \%$, unlikely; $25 \%$ to $75 \%$, possibly; $75 \%$ to $95 \%$, likely; $95 \%$ to $99.5 \%$, very likely; $>99.5 \%$, most likely. ${ }^{13}$ The fixed effects from continuous race factors were multiplied by 2 SD before interpreting the magnitude of the effect, which can be interpreted as the difference between a typically low and typically high influence of that race factor. ${ }^{13}$ The magnitude of changes over time was calculated as the accumulated change over 10 years. Thresholds for interpreting magnitudes of differences in mean performances as being small, moderate, large, very large, and extremely large were calculated as $0.3,0.9,1.6,2.5$, and 4.0 , respectively, of the withinathlete within-season race-to-race $\mathrm{CV}$ (residual) in total race time for annual top-10 athletes (and trivial below 0.3 ). For performance times, these differences would result in 1, 3, 5, 7, and 9 extra medals in every 10 competitions for a top athlete already winning medals regularly. ${ }^{13}$ Effects with confidence limits (CL) overlapping the thresholds for both small positive and small negative effects were deemed unclear. The CVs were doubled before their magnitude on the described scale was assessed. ${ }^{3,13}$ Magnitude thresholds for the total race time were recalculated into specific thresholds for the skiing time, shooting times, and proportion of hits, so that the smallest worthwhile enhancement corresponded for all dependent variables in time (s). The thresholds for proportion of hits were calculated assuming that the penalty loop took 23 and 25 seconds for men and women, respectively, and were expressed as a proportion ratio assuming a reference proportion of 0.90 (approximately the mean proportion of hits for top-10 athletes).

Predictability of performance times, expressed as the intraclass correlation coefficient (ICC) between 2 races within a season and between 2 races in 2 different seasons, was calculated from the variances associated with the random effects and the residual using Equations 1 and 2, respectively:

$$
\begin{aligned}
& \text { Within-season ICC } \\
& \qquad=\frac{\text { athleteID }^{2}+(\text { athleteID } \times \text { season })^{2}}{\text { athleteID }^{2}+(\text { athleteID } \times \text { season })^{2}+\text { residual }^{2}}
\end{aligned}
$$

Between-seasons ICC

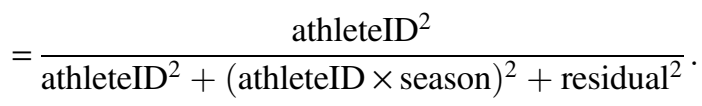

The magnitude of the ICCs was assessed using the following scale: .15, low; .36, moderate; .54, high; .69, very high; and .83, extremely high. 3,8 
The uncertainty of all estimates is shown as 90\% CLs in plus/ minus form $( \pm)$ for fixed effects and as times/divided-by form $(\times / \div)$ for $\mathrm{CVs} / \mathrm{SDs}$. CLs for the ICCs were calculated from the $F$ ratio for the within- and between-athletes sources of variation and are shown in an approximate \pm form. ${ }^{3,16}$

\section{Results}

\section{Variability}

The within-athlete within-season race-to-race variability showed most likely trivial differences between sexes and between all athletes and top-10 athletes (Tables 3 and 4). There were also most likely trivial differences between variability among races within a season and between seasons. The variabilities followed the order: total race time (large) $>$ proportion of hits (moderate) $\approx$ skiing time (moderate) $>$ shooting times (trivial).

The differences in between-athletes variability between top-10 athletes and all athletes were most likely large to extremely large for the total race time and skiing time (top-10< all athletes), most likely trivial for shooting times, and trivial to small for proportion of targets hit. The majority of between-athletes variabilities showed trivial sex differences. However, skiing time differed for top-10 athletes (small; women $>$ men). Between-events CVs were very large for both the skiing $(\sim 5-6 \%)$ and total race time $(\sim 4-5 \%)$, trivial for the shooting times $(\sim 4-8 \%)$, and trivial to small for the proportion of targets hit $(0-5 \%)$.

The variability in total race time provided here derived smallest worthwhile enhancements of $0.75 \%(0.3 \times 2.5 \%)$ and $0.87 \%$ $(0.3 \times 2.9 \%)$ for men and women, respectively. This corresponds to changes of $0.82 \%\left(\delta^{\star}\right)$ and $0.97 \%$ (o) for skiing time, $37 \%\left({ }^{\star}\right)$ and $35 \%$ (ㅇ) for prone shooting time, and $41 \%$ ( $\left.\sigma^{*}\right)$ and $36 \%$ (ㅇ) for standing shooting time. For 5 and 10 shots, thresholds for the proportion ratios are 1.10 (increase) and 0.90 (decrease) and 1.05 and 0.95 , respectively.

\section{Predictability}

The predictability of performance expressed as ICC was similar within and between seasons (trivial difference, Table 3). For all athletes, within- and between-seasons ICCs were very high to extremely high for both the skiing time and total race time and moderate to high for shooting times. For top-10 athletes, ICCs were only trivial to moderate.

Within-season ICCs were most likely larger for all athletes than for top-10 athletes with regard to the total race time (very large difference), skiing time (moderate to large difference), and prone and standing shooting times (small differences).

Top-10 women had most likely higher within- and betweenseasons ICCs for skiing time than men (small difference), but the sexes did not differ with respect to other ICCs.

\section{Fixed Effects}

All effects from race factors were derived from generalized linear mixed models analyzing annual top-10 athletes. The effects of race factors on the total race time, skiing time, and shooting times are presented in Table 5 per unit change and as effect magnitudes evaluated as a 2-SD change of each race factor. Soft track conditions had a possibly larger effect for women than men (mean difference, $\pm 90 \%$ CL: $1.7, \pm 2.3 \%$, small), with the remaining race factors showing trivial or unclear sex differences.

The proportion ratios of targets hit for a 2-SD change in wind speed, a 2-SD change in altitude, changes between 2005 and 2015, and differences between Championships and WCs were possibly to most likely trivial for prone and standing shooting when analyzed separately (range 0.92-1.03). However, for both shootings combined, a 2-SD increase in wind speed reduced the proportion of hits possibly by a small effect (proportion ratio: $0.95, \times / \div 1.02$, both men and women), with all other effects being very likely to most likely trivial (proportion ratios 0.98-1.02).

\section{Discussion}

The present study provides novel insights about variability and predictability in addition to the race factors affecting performance in elite biathlon. Furthermore, the within-athlete race-to-race variability documented here provides estimates of the smallest worthwhile performance enhancement.

Table 4 Within- and Between-Athletes Variability in Proportion of Targets Hit ( $n$ out of 5 or 10) Expressed as Standard Deviation (SD) in Proportion Units (\%) for the Prone and Standing Shooting for All Athletes and for Annual Top-10 Athletes

\begin{tabular}{|c|c|c|c|c|c|c|}
\hline & \multicolumn{3}{|c|}{ All Athletes } & \multicolumn{3}{|c|}{ Top-10 Athletes } \\
\hline & \multicolumn{2}{|c|}{ Within-Athlete SD (\%) } & \multirow[b]{2}{*}{$\begin{array}{c}\text { Between- } \\
\text { athletes SD (\%) }\end{array}$} & \multicolumn{2}{|c|}{ Within-Athlete SD (\%) } & \multirow[b]{2}{*}{$\begin{array}{c}\text { Between- } \\
\text { athletes SD (\%) }\end{array}$} \\
\hline & $\begin{array}{l}\text { Within } \\
\text { season }\end{array}$ & $\begin{array}{l}\text { Between } \\
\text { seasons }\end{array}$ & & $\begin{array}{l}\text { Within } \\
\text { season }\end{array}$ & $\begin{array}{l}\text { Between } \\
\text { seasons }\end{array}$ & \\
\hline \multicolumn{7}{|l|}{ Men } \\
\hline prone shooting ( 5 shots) & 16.5 & 16.7 & 6.5 & 13.4 & 13.6 & 0.0 \\
\hline standing shooting ( 5 shots) & 17.9 & 18.2 & 8.3 & 15.9 & 16.2 & 1.9 \\
\hline both shootings (10 shots) & 12.1 & 12.2 & 6.9 & 10.6 & 10.8 & 0.0 \\
\hline \multicolumn{7}{|l|}{ Women } \\
\hline prone shooting ( 5 shots) & 16.3 & 16.5 & 6.0 & 13.8 & 13.8 & 3.4 \\
\hline standing shooting ( 5 shots) & 17.5 & 17.8 & 8.2 & 14.8 & 15.0 & 4.7 \\
\hline both shootings (10 shots) & 11.8 & 12.1 & 6.6 & 10.1 & 10.1 & 3.5 \\
\hline
\end{tabular}


Table 5 Effect of Race Factors on the Total Race Time, Skiing Time, and Shooting Time in Biathlon Sprints

\begin{tabular}{|c|c|c|c|c|}
\hline & \multicolumn{2}{|c|}{ Men } & \multicolumn{2}{|c|}{ Women } \\
\hline & Effect; $\pm 90 \%$ CL (\%) & Magnitude of effect & Effect; $\pm 90 \%$ CL (\%) & Magnitude of effect \\
\hline \multicolumn{5}{|l|}{ Total race time } \\
\hline Championship vs WC & $-2.9 ; \pm 2.4$ & Moderate** & $-1.8 ; \pm 2.6$ & Small* \\
\hline soft vs hard snow condition & $2.2 ; \pm 1.6$ & Small** & $3.9 ; \pm 1.7$ & Moderate $* * * *$ \\
\hline altitude $(1000 \mathrm{~m})$ & $1.7 ; \pm 1.5$ & Small** & $2.0 ; \pm 1.7$ & Small** \\
\hline track gradient $(1 \%)$ & $4.9 ; \pm 2.2$ & Moderate $* * * *$ & $5.1 ; \pm 2.1$ & Moderate $* * * *$ \\
\hline wind $(1 \mathrm{~m} / \mathrm{s})$ & $1.7 ; \pm 0.7$ & Moderate $* * * *$ & $1.2 ; \pm 0.7$ & Moderate $* * *$ \\
\hline change over 10 seasons & $-4.5 ; \pm 2.4$ & Large $* * *$ & $-6.4 ; \pm 2.6$ & Large $* * * *$ \\
\hline \multicolumn{5}{|l|}{ Skiing time } \\
\hline Championship vs WC & $-2.7 ; \pm 2.5$ & Moderate** & $-1.9 ; \pm 2.8$ & Small* \\
\hline soft vs hard snow condition & $2.2 ; \pm 1.6$ & Small** & $3.8 ; \pm 1.8$ & Moderate $* * *$ \\
\hline altitude $(1000 \mathrm{~m})$ & $1.7 ; \pm 1.6$ & Small** & $1.5 ; \pm 1.8$ & Small* \\
\hline track gradient $(1 \%)$ & $4.5 ; \pm 2.2$ & Moderate $* * *$ & $4.9 ; \pm 2.2$ & Moderate $* * * *$ \\
\hline change over 10 seasons & $-4.2 ; \pm 2.5$ & Moderate $* * *$ & $-6.1 ; \pm 2.8$ & Large $* * * *$ \\
\hline \multicolumn{5}{|l|}{ Prone shooting time } \\
\hline Championship vs WC & $-2.6 ; \pm 3.1$ & Trivial & $-1.1 ; \pm 2.9$ & Trivial \\
\hline altitude $(1000 \mathrm{~m})$ & $1.3 ; \pm 1.8$ & Trivial & $1.9 ; \pm 1.9$ & Trivial \\
\hline wind $(1 \mathrm{~m} / \mathrm{s})$ & $2.3 ; \pm 0.9$ & Trivial & $1.7 ; \pm 0.8$ & Trivial \\
\hline change over 10 seasons & $-8.3 ; \pm 4.2$ & Trivial & $-7.3 ; \pm 4.5$ & Trivial \\
\hline \multicolumn{5}{|l|}{ Standing shooting time } \\
\hline Championship vs WC & $-0.5 ; \pm 4.7$ & Trivial & $0.3 ; \pm 4.0$ & Trivial \\
\hline altitude $(1000 \mathrm{~m})$ & $1.0 ; \pm 3.0$ & Trivial & $3.4 ; \pm 2.7$ & Trivial \\
\hline wind $(1 \mathrm{~m} / \mathrm{s})$ & $3.3 ; \pm 1.4$ & Trivial & $3.5 ; \pm 1.1$ & Trivial \\
\hline change over 10 seasons & $-9.1 ; \pm 5.9$ & Trivial & $-4.9 ; \pm 5.4$ & Trivial \\
\hline
\end{tabular}

Abbreviation: CL, confidence limits; WC, World Cup.

Note: Effects are derived from analysis of annual top-10 athletes. Before evaluation of effect magnitudes, effect sizes of continuous race factors were calculated as their effect per unit change multiplied with 2 SDs of the race factor to illustrate the difference between a typically low and typically high influence of that race factor. The changes over time were evaluated as the accumulated effect over 10 years.

Probability of effects: *possibly (25-75\%); **likely (75-95\%); ***very likely $(95-99.5 \%)$; ****most likely (>99.5\%). All trivial effects were most likely.

The within-athlete race-to-race variability in total race time in biathlon sprints is in the upper range compared with most endurance sports $(0.3-2.4 \%) .{ }^{3-5,8}$ We believe that this is caused by the 2-component characteristic of biathlon, similar to what is found in orienteering, where the athletes need to both run fast and navigate correctly (top-45 athletes: $3.2-7.0 \%) .{ }^{7}$ Hence, when focusing on the isolated variability in skiing time for biathletes $(1.5 \%)$, the variability was comparable to that found in cross-country skiing $(1.1-1.4 \%) .{ }^{8}$ Moreover, there were substantial CVs for the shooting times $(11-15 \%)$ and SDs for the proportion of hits $(\sim 13-16 \%$ at each shooting). However, when multiplied by mean performance times for annual top-10 athletes, the race-to-race variability ranged from only 3.5 to 4.5 seconds for the shooting times (trivial in magnitude) compared with 18 to 21 seconds for the skiing time (moderate). Since the variability in proportion of hits combined for both shootings was approximately 1 target $(\sim 10 \%$ in 10 shots $\approx$ \pm 1 hit) and finishing a penalty loop takes $\sim 23$ to 25 seconds, the variabilities in proportion of hits and skiing time are comparable in seconds.

No substantial sex difference was found in within-athlete variability, meaning both sexes performed with similar consistency from race to race. Similar within-athlete variability is in contradiction to other sports such as cross-country skiing, ${ }^{8}$ cycling, ${ }^{4}$ slalom canoe, and kayaking, ${ }^{17}$ where larger variability is found for women than men, but is similar to rowing ${ }^{3}$ and speed skating. ${ }^{5}$ Previously, it has been shown that proficiency influences within-athlete variability, with the best athletes showing lower variability than lowerranked athletetes. ${ }^{4,6,8,17,18}$ However, in the present study we did not find any difference between all athletes and top-10 athletes, meaning that all levels of biathletes might be expected to vary similarly in performance between races.

In addition, the within-season and between-seasons variabilities were similar in the present study, indicating that biathletes' performance is quite stable from season to season, a finding in agreement with data from cross-country skiing ${ }^{8}$ and rowing. ${ }^{3}$ For all athletes, the magnitudes of between-athletes variabilities were largest for skiing time (very large), followed by proportion of hits (small) and shooting times (trivial). This pattern was also evident for top-10 athletes and indicates skiing time as the major distinguishing factor between athletes.

Skiing time was the most consistent performance variable, showing extremely high ICCs for all athletes. However, all ICCs declined markedly when analyzed for top-10 athletes, a finding that is in agreement with other sports. ${ }^{5,8}$ Reduced ICCs are believed to be a result of the superior depth of competition for top-10 athletes, ${ }^{5,8}$ which is illustrated here by the reduced between-athletes variability for this selected group compared with all athletes.

The effect of competition importance on total race time was somewhat higher than in speed skating $(\sim 0.3 \%)^{5}$ and swimming $(\sim 0.9 \%)^{6}$ but lower than in rowing $(2.7-4.1 \%) .{ }^{3}$ It is interesting that 
this was caused entirely by faster skiing times, since shooting times and proportion of hits were similar at WC and World Championships. This may be due to athletes' peaking for major events or other factors outside the scope of this research design, such as better track preparation, more optimized glide due to larger service teams supporting fewer numbers of athletes, ergogenic aids, pacing strategies, doping, and so forth. Moreover, the limited number of World Championship races $(\mathrm{n}=11)$ compared with World Cup races $(n=98-99)$ and the large confidence limits should be taken into consideration when interpreting the results.

A $1000-\mathrm{m}$ increase in altitude had a moderate negative effect on skiing time and consequently a small negative effect on total race time (1.7-2\%), with the negative effect being similar to that seen in 1500 - to $10,000-\mathrm{m}$ track running $(1.1-2.4 \%)^{19}$ and distance $(>10 \mathrm{~km})$ cross-country skiing $(0.3-2.0 \%) .{ }^{8}$ The negative effect of altitude is presumably caused by the decrease in partial pressure of oxygen that causes $\mathrm{VO}_{2} \max$ to decline by $\sim 6 \%$ per $1000-\mathrm{m}$ increase in altitude. ${ }^{20}$ Not surprisingly, increasing the meters climbed relative to the race length increased skiing time and, hence, total race time. Moreover, the present analysis found clear negative effects of soft compared with hard track conditions on both skiing and total time. This finding is to some extent comparable to an analysis of international cross-country skiing, where substantial $(>2 \%)$ negative effects were found with some snow conditions; however, the effect was unclear and inconsistent between events. ${ }^{8}$

In addition, an increase in wind speed at the shooting range reduced the proportion of hits at both shootings combined (by a small effect) and consequently increased the total race time moderately. This was presumably caused by the more challenging shooting conditions at high wind speeds, potentially with more movement of the body/rifle and increased difficulty in anticipating the impact of the wind on the bullet's trajectory.

Furthermore, the present analysis found large improvements in total race time over the last decade, which was caused by moderate to large improvements in skiing time, since the proportion of hits and shooting times were practically unchanged. We speculate that better track preparation, improved skiing equipment, and more effective training have contributed to these changes. Finally, there were very large between-events CVs for both skiing and total times, meaning that the present analyses' fixed effects did not cover all variability in terms of the track layouts and environmental effects. However, this form of variability was trivial to small for the shooting times and proportion of hits, presumably since the shooting conditions are more standardized than the track layouts between events.

\section{Practical Applications}

The smallest worthwhile enhancement for world-class athletes is considered to be 0.3 times the within-athlete race-to-race variability. ${ }^{2,13}$ This emphasizes that training interventions, ergogenic aids, recovery strategies, and equipment that increase male and female biathletes' performance by at least $0.8 \%$ and $0.9 \%$, respectively, would have a substantial effect on total race time. For the sprint event, this corresponds to performance enhancements of $\sim 12$ seconds for top-10 men and women, which is approximately the same as the mean time gap between first and second place and between third and fifth place in international sprint events (data not shown). This emphasizes that performance improvements in the magnitude of the smallest worthwhile enhancement indeed lead to meaningful changes for biathletes competing at the highest level. We therefore encourage researchers and coaches working with top athletes to use these thresholds when interpreting the magnitude and meaningfulness of interventions they may implement to improve medal-winning chances. However, we need to point out that the average performance improvements between WC and major championships can be as high as $\sim 2 \%$ to $3 \%$. Therefore, we suggest that performance strategies constructed to enhance performance by $\sim 2 \%$ to $3 \%$ toward championships may be necessary to maintain relative performance, and, consequently, even larger enhancements may be needed to exceed competitors' improvements.

\section{Conclusions}

Biathletes typically vary by $2.5 \%$ to $3.2 \%$ in performance from race to race, with the isolated variability being similar for the proportion of hits and skiing time but lower for the shooting time expressed in seconds. In addition, race importance, altitude, track gradient, snow conditions, and wind conditions affect skiing and shooting performance and subsequently total race time in biathlon sprints.

\section{Acknowledgments}

We would like to thank Professor Will Hopkins for valuable training in generalized linear mixed modeling preceding these analyses. The authors have no conflicts of interest or financial disclosures to report.

\section{References}

1. Hoffman MD, Street GM. Characterization of the heart rate response during biathlon. Int J Sports Med. 1992;13:390-394. PubMed doi: 10.1055/s-2007-1021286

2. Hopkins WG, Hawley JA, Burke LM. Design and analysis of research on sport performance enhancement. Med Sci Sports Exerc. 1999; 31:472-485. PubMed doi:10.1097/00005768-199903000-00018

3. Smith TB, Hopkins WG. Variability and predictability of finals times of elite rowers. Med Sci Sports Exerc. 2011;43:2155-2160. PubMed doi:10.1249/MSS.0b013e31821d3f8e

4. Paton CD, Hopkins WG. Variation in performance of elite cyclists from race to race. Eur J Sport Sci. 2006;6:25-31. doi:10.1080/ 17461390500422796

5. Noordhof DA, Mulder RC, de Koning JJ, Hopkins WG. Race factors affecting performance times in elite long-track speed skating. Int $J$ Sports Physiol Perform. 2016;11:535-542. PubMed doi:10.1123/ ijspp.2015-0171

6. Pyne D, Trewin C, Hopkins W. Progression and variability of competitive performance of Olympic swimmers. J Sports Sci. 2004; 22:613-620. PubMed doi:10.1080/02640410310001655822

7. Hebert-Losier K, Platt S, Hopkins WG. Sources of variability in performance times at the World Orienteering Championships. Med Sci Sports Exerc. 2015;47:1523-1530. PubMed doi:10.1249/MSS. 0000000000000558

8. Spencer M, Losnegard T, Hallén J, Hopkins WG. Variability and predictability of performance times of elite cross-country skiers. Int $J$ Sports Physiol Perform. 2014;9:5-11. PubMed doi:10.1123/ijspp. 2012-0382

9. Tønnessen E, Haugen TA, Hem E, Leirstein S, Seiler S. Maximal aerobic capacity in the winter-Olympics endurance disciplines: Olympic-medal benchmarks for the time period 1990-2013. Int J Sports Physiol Perform. 2015;10:835-839. doi:10.1123/ijspp.2014-0431

10. Rundell KW, Bacharach DW. Physiological characteristics and performance of top U.S. biathletes. Med Sci Sports Exerc. 1995;27: 1302-1310. PubMed 
11. Rundell KW. Treadmill roller ski test predicts biathlon roller ski race results of elite U.S. biathlon women. Med Sci Sports Exerc. 1995; 27:1677-1685. PubMed

12. Tønnessen E, Sylta Ø, Haugen TA, Hem E, Svendsen IS, Seiler S. The road to gold: training and peaking characteristics in the year prior to a gold medal endurance performance. PLoS One. 2014;9:e101796. doi:10.1371/journal.pone.0101796

13. Hopkins WG, Marshall SW, Batterham AM, Hanin J. Progressive statistics for studies in sports medicine and exercise science. Med Sci Sports Exerc. 2009;41:3-13. PubMed doi:10.1249/MSS. 0b013e31818cb278

14. Hopkins W. SAS (and R) for mixed models. Spreadsheet: process Poisson and logistic repeated measures. Sportscience. 2016;20, iii. http://www.sportsci.org/2016/inbrief.htm\#SAS. Accessed November 28, 2016.

15. Hopkins WG. A spreadsheet for combining outcomes from several subject groups. Sportscience. 2006;10:51-53.
16. Hopkins WG. Calculating the reliability intraclass correlation coefficient and its confidence limits (Excel spreadsheet). Sportscience, 2009. http://www.newstats.org/xICC.xls.

17. Nibali M, Hopkins WG, Drinkwater E. Variability and predictability of elite competitive slalom canoe-kayak performance. Eur J Sport Sci. 2011;11:125-130. doi:10.1080/17461391.2010.487121

18. Bullock N, Hopkins WG, Martin DT, Marino FE. Characteristics of performance in skeleton World Cup races. J Sports Sci. 2009;27: 367-372. PubMed doi:10.1080/02640410802613425

19. Hollings SC, Hopkins WG, Hume PA. Environmental and venuerelated factors affecting the performance of elite male track athletes. Eur J Sport Sci. 2012;12:201-206. doi:10.1080/17461391.2011. 552640

20. Wehrlin JP, Hallen J. Linear decrease in $\mathrm{VO}_{2}$ max and performance with increasing altitude in endurance athletes. Eur J Appl Physiol. 2006;96:404-412. PubMed doi:10.1007/s00421-0050081-9 